\title{
A SAZONALIDADE DA QUALIDADE DO AR NO ESTADO DE SÃO PAULO
}

\section{Thiago Souza Silveira ${ }^{1}$}

\section{Maria Elisa Siqueira Silva ${ }^{2}$}

RESUMO: Com enfoque na climatologia geográfica, o presente trabalho discute a sazonalidade da qualidade do ar no estado de São Paulo relacionada aos poluentes decorrentes da queima de cana-de-açúcar, através da análise da situação da dispersão de poluentes ao longo do ano de 2010 para este estado associando-as ao ciclo produtivo de cana-de açúcar. Foram utilizados dados observacionais e de sensoriamento remoto visando saber as condições atmosféricas, as áreas plantadas e a qualidade do ar aferida pelas estações da CETESB (Companhia de Tecnologia de Saneamento Ambiental de São Paulo). Os poluentes selecionados foram Monóxido de Carbono (CO) e o Material Particulado $\left(\mathrm{MP}_{10}\right)$, pois ambos possuem ampla cobertura de estações de medição e são subprodutos da queima de biomassa. Resultados preliminares demonstraram uma coincidência entre a piora da qualidade do ar com o aumento dos pontos de queimada detectados por satélite e o auge da colheita de cana no estado. Tais resultados nos permitem notar que realmente ocorre piora da qualidade do ar, ao menos durante a colheita, agravada pelas condições atmosféricas propícias a permanência destes poluentes em suspensão. Assim, a expansão das áreas plantadas, associadas ao incentivo da produção de biocombustíveis, podem intensificar o fenômeno e afetar a saúde da população.

\footnotetext{
${ }^{1}$ Mestrando, Universidade de São Paulo. thiagosousilveira@usp.br. (Bolsista CAPES)

${ }^{2}$ Professora, Universidade de São Paulo.
} 
Palavras-Chave: Cana-de-açúcar; Poluição Atmosférica; Saúde Pública

\section{INTRODUÇÃO}

A introdução da cultura de biocombustíveis no país surgiu na década de 1970, após o choque do petróleo, com a criação do programa Proálcool e, desde então, o país domina a tecnologia desde o plantio até a distribuição do produto. Isso coloca o Brasil e o estado de São Paulo como os maiores produtores de alimentos e de biocombustíveis do país (IBGE, 2006; FOOD AND AGRICULTURE ORGANIZATION OF THE UNITED NATIONS, 2011). Hoje em dia, no estado, há 20.512 fazendas de cana, gerando 11 bilhões de reais e 240 milhões de toneladas produzidas (entre açúcar, etanol e aguardente) em mais de 5 milhões de hectares (IBGE, 2006).

Os procedimentos de cultivo da cana não sofreram muitas modificações desde sua implantação no Brasil por Tomé de Souza, no século XVI (CAVALCANTE, 2011), e, por isso, a queima da palha do canavial ainda é uma prática recorrente para desidratar o pé, afastar animais peçonhentos e facilitar o corte do caule. Por outro lado, as consequências desses atos são: a mortalidade de animais, interrupção do fornecimento de energia, baixa visibilidade nas estradas e, principalmente, poluição do ar e problemas de saúde na população (BARROCAS, 2001; ARBEX et al., 2004)

Complementando a problemática, o ápice da colheita de cana ocorre nos meses mais secos do ano para o estado de São Paulo, agosto e setembro (INSTITUTO NACIONAL DE METEOROLOGIA, 1991), não permitindo a decantação de substâncias poluentes, prejudicando a qualidade do ar.

Desta forma, este estudo buscou avaliar a poluição atmosférica de Monóxido de Carbono (CO) e Material Particulado ( $\left.\mathrm{MP}_{10}\right)$ no estado de São Paulo quanto sua taxa de emissão, espacialidade e sazonalidade. 


\section{MÉTODOS}

Para elaborar esse estudo foram usados dados observados por sensoriamento remoto, através da constelação de satélites disponíveis para pesquisas agrícolas, ambientais e de recursos naturais, como os sensores do satélite Aqua, Terra e Landsat, por exemplo.

Essas imagens foram analisadas pelo INPE (Instituto Nacional de Pesquisas Espaciais) por diferentes grupos de estudos, um que verifica a quantidade de pontos quentes na superfície terrestre, que pode sugerir episódios de queimadas (GONTIJO et al., 2011). E outro, que estuda a dimensão da área plantada de cana-de-açúcar no país, como o programa CANASAT.

Outro dado observado é o boletim de qualidade do ar da CETESB (Companhia de Tecnologia de Saneamento Ambiental de São Paulo) que indica a qualidade do ar segundo as estações de aferição espalhadas pelo estado.

O cruzamento de dados de onde o ar está poluído e quais locais são produtores de cana ajudam na investigação da influência da queima da cana na qualidade do ar.

Analisando o comportamento atmosférico dos dias mais poluídos foi possível conhecer quais as melhores condições para a concentração de $\mathrm{MP}_{10}$ e $\mathrm{CO}$ no ar. Esses dados são fornecidos pelo INMET (Instituto Nacional de Meteorologia), Marinha do Brasil e CPTEC (CENTRO DE PREVISÃO DE TEMPO E ESTUdOS CLIMÁTICOS), POR EXEMPLO.

\section{RESULTADOS}

Quantidade de poluentes emitidos em 2010 
Para analisar a quantidade de poluentes medidos em 2010 pelas estações de qualidade do ar, foi levantado o histórico de todas as medições de $\mathrm{CO}$ e $\mathrm{MP}_{10}$ para todos os dias e todas as horas do ano. Em seguida classificá-los segundo os critérios da CETESB de taxas e status, gerando o Quadro 1 que posteriormente foi posicionado segundo suas médias no período (Gráfico 1 e Gráfico 2).

\begin{tabular}{|lc|lc|}
\hline \multicolumn{4}{|c|}{ Classificação da CETESB } \\
\hline \multicolumn{2}{|c|}{ Classificação CO } & \multicolumn{2}{c|}{ Classificação } \\
\hline Boa & Até 4,50 & Boa & Até 50,00 \\
\hline Regular & 9 & Regular & 150 \\
\hline Inadequada & 15 & Inadequada & 250 \\
\hline Má & 30 & Má & 420 \\
\hline Péssima & $>30,00$ & Péssima & $>420,00$ \\
\hline
\end{tabular}

Quadro 1. Classificação da CETESB segundo os níveis de poluição por $\mathrm{CO}$ e $\mathrm{MP}_{10}$ Fonte: CETESB (2010)

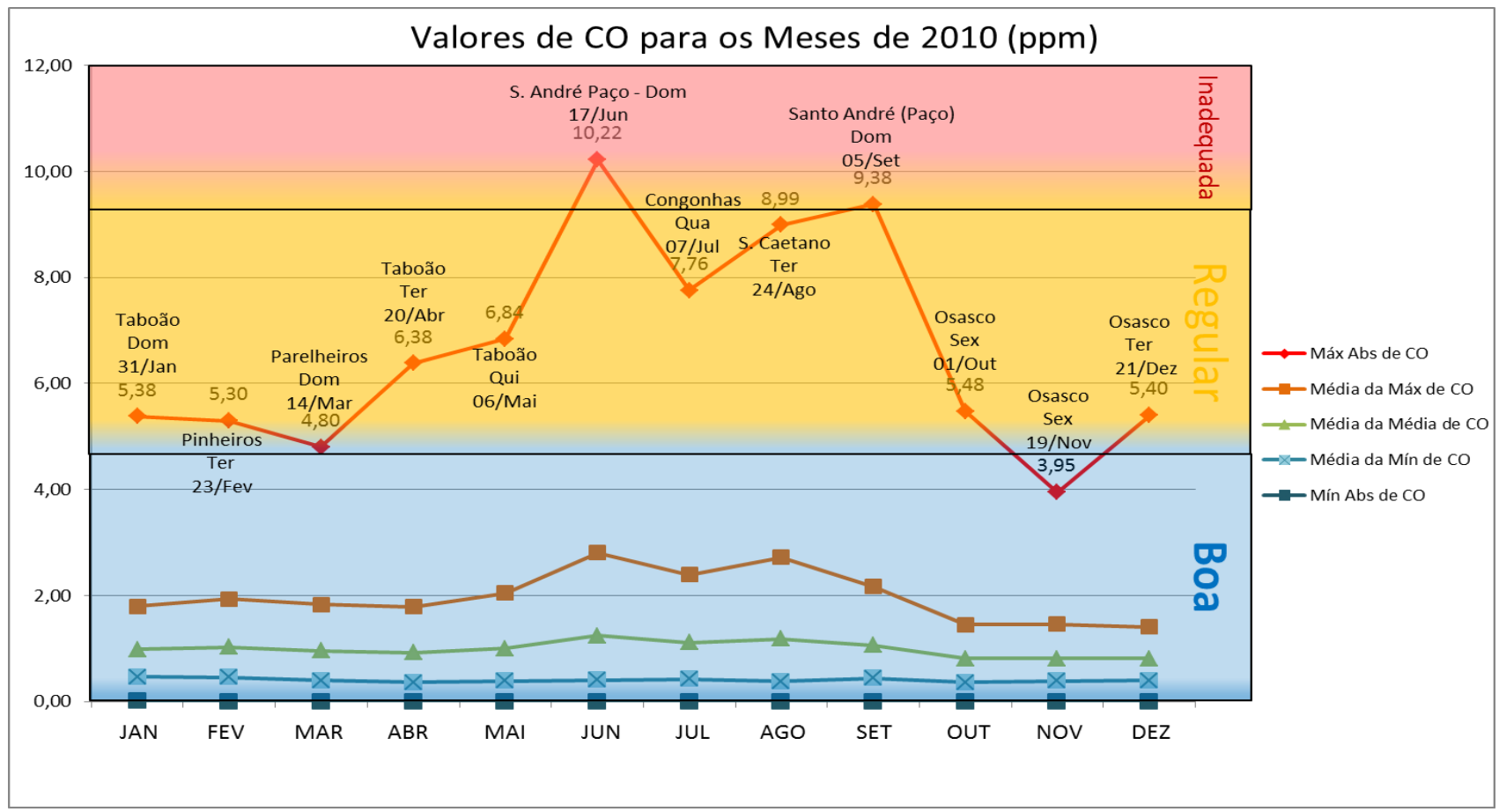

Gráfico 1: Valor médio e absoluto da concentração mensal de CO em 2010 Fonte: CETESB (2012) 


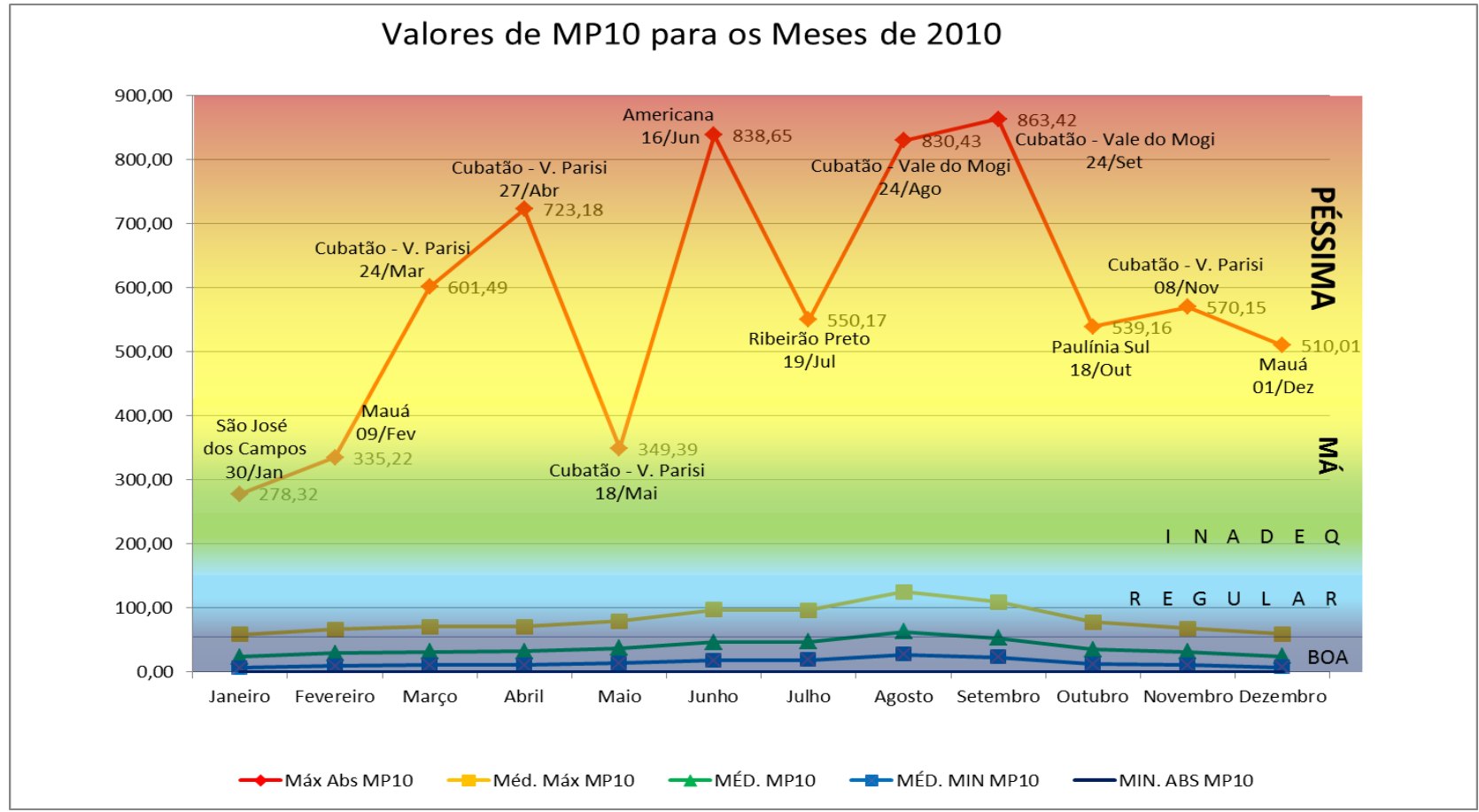

Gráfico 2: Valores de material particulado mensal para 2010

Fonte: CETESB (2012)

Quanto ao gráfico referente ao $\mathrm{MP}_{10}$ observa-se grande oscilação das máximas absolutas quando comparado às demais linhas de médias e absolutas, isto já não ocorre quando consideramos o gráfico de $\mathrm{CO}$, cujo comportamento mostra-se mais uniforme. Nota-se que o mês de junho foi o mais poluído para $\mathrm{CO}$ e o segundo maior para $\mathrm{MP}_{10}$. Enquanto a situação inversa ocorreu no mês de setembro, não estando, a priori, relacionados ao mesmo sistema atmosférico, pois o segundo maior registro de $\mathrm{CO}$ foi no início do mês e o de $\mathrm{MP}_{10}$ no final.

\section{A Espacialidade da Poluição por $\mathrm{CO}$ e $\mathrm{MP}_{10}$}

Conhecendo a taxa de poluição, principalmente com relação ao seu máximo absoluto não significa que o estado todo está poluído, para isso é necessário entender a sua espacialização, onde está ocorrendo mais poluição e quando ela ocorre. 
Para isso foi elaborado um mapa de dispersão de poluentes, no qual as estações são marcadas com cores segundo o seu status relativo ao pior resultado do mês e as demais estações segundo o pior resultado daquele dia, fazendo uma análise do dia mais poluído do mês, para todos os meses (Mapa 1 e

\section{Mapa 2).}
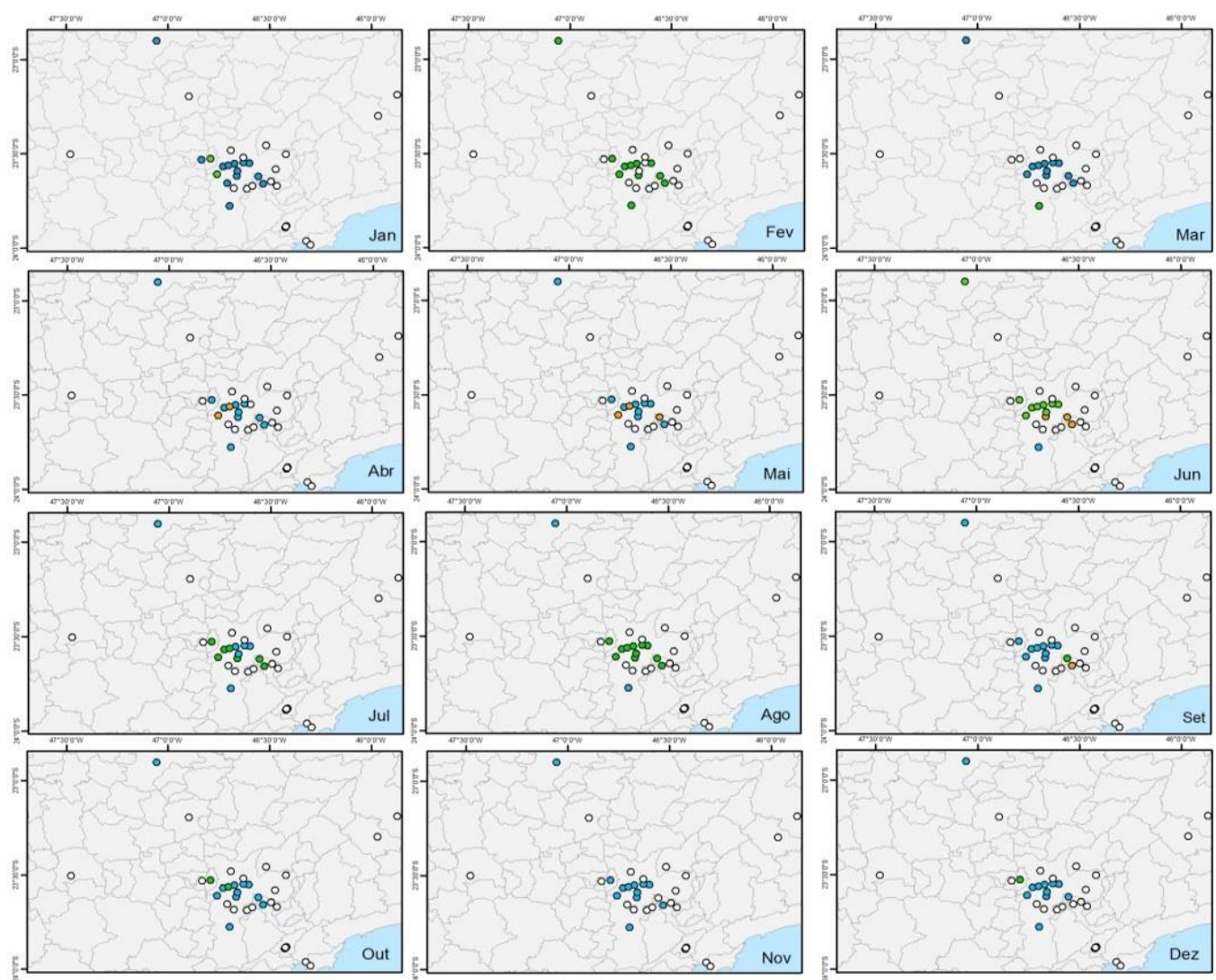

Prancha de Distribuição Espacial de Monóxido de Carbono: máxima absoluta mensal

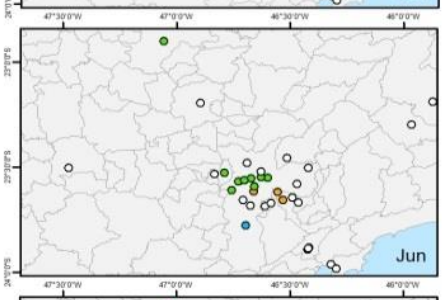

Legenda

- Sem Dado ○ Inadequada

- Boa Ma

- Regular - Pessima
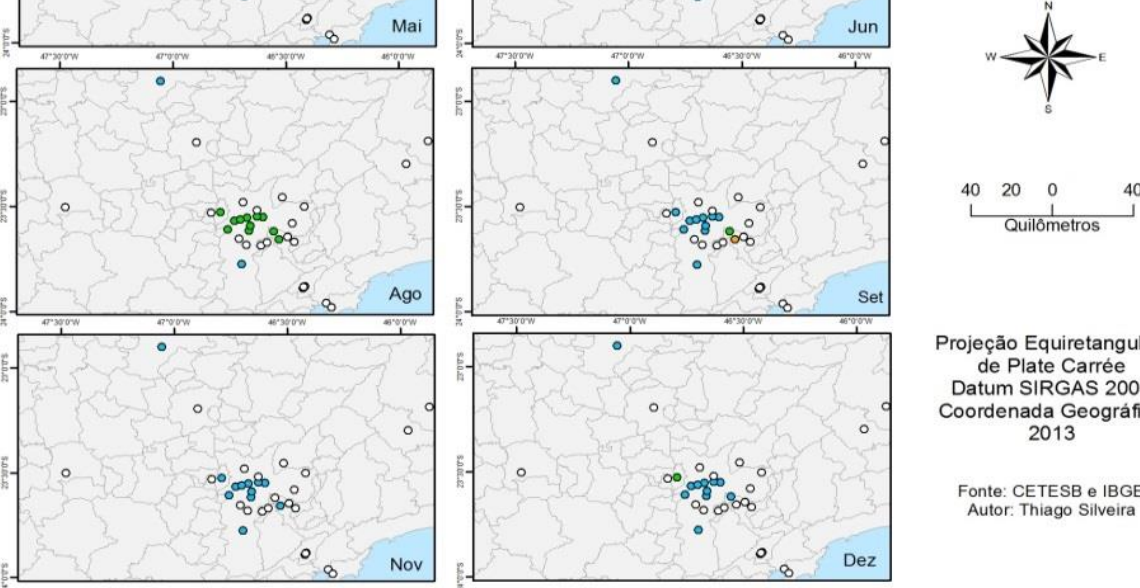

Projeção Equiretangular de Plate Carree Datum SIRGAS 2000 Coordenada Geográfica 2013

Fonte: CETESB e IBGE

Mapa 1: Prancha de distribuição espacial de monóxido de carbono no pior dia de cada mês de 2010. Fonte: CETESB e IBGE 
Prancha de Distribuição Espacial de Material Particulado: máxima absoluta mensal
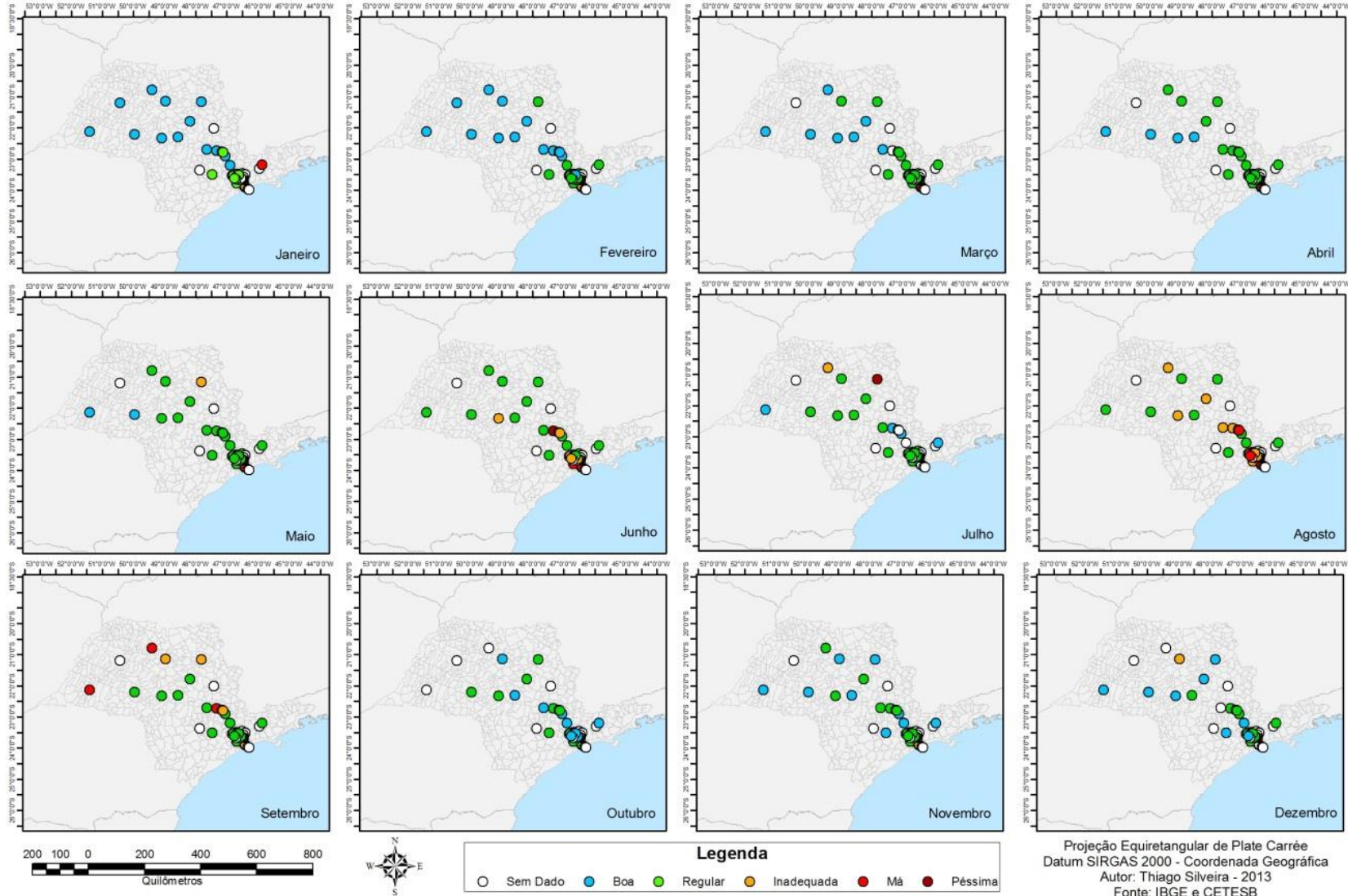

Mapa 2: Prancha de distribuição espacial de material particulado no pior dia de cada mês de 2010. Fonte: CETESB e IBGE

Essa análise foi feita para as estações medidoras de $\mathrm{CO}$ e de $\mathrm{MP}_{10}$, para todo 0 estado de São Paulo, e percebeu-se uma sazonalidade da poluição atmosférica em cidades não-industriais por excelência, como São José do Rio Preto, Ribeirão Preto. Por acaso, esses municípios são produtores de cana (IBGE, 2006) e a sua piora na qualidade do ar se dá justamente na época de colheita. Como o procedimento de queima é comum, foi realizado um mapeamento de todos os eventos para o ano de 2010 e observou-se também uma sazonalidade compatível com os meses secos do estado (

Mapa 3). 

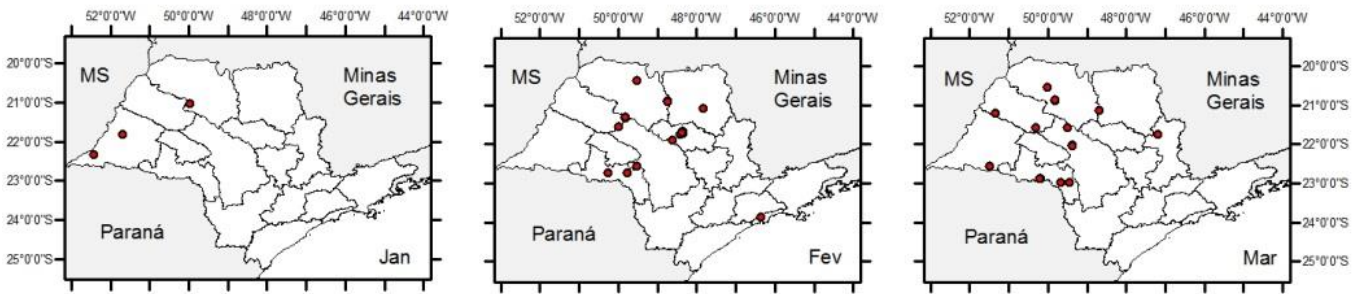

\section{Ocorrência de \\ Queima de \\ Biomassa \\ no estado de \\ São Paulo}
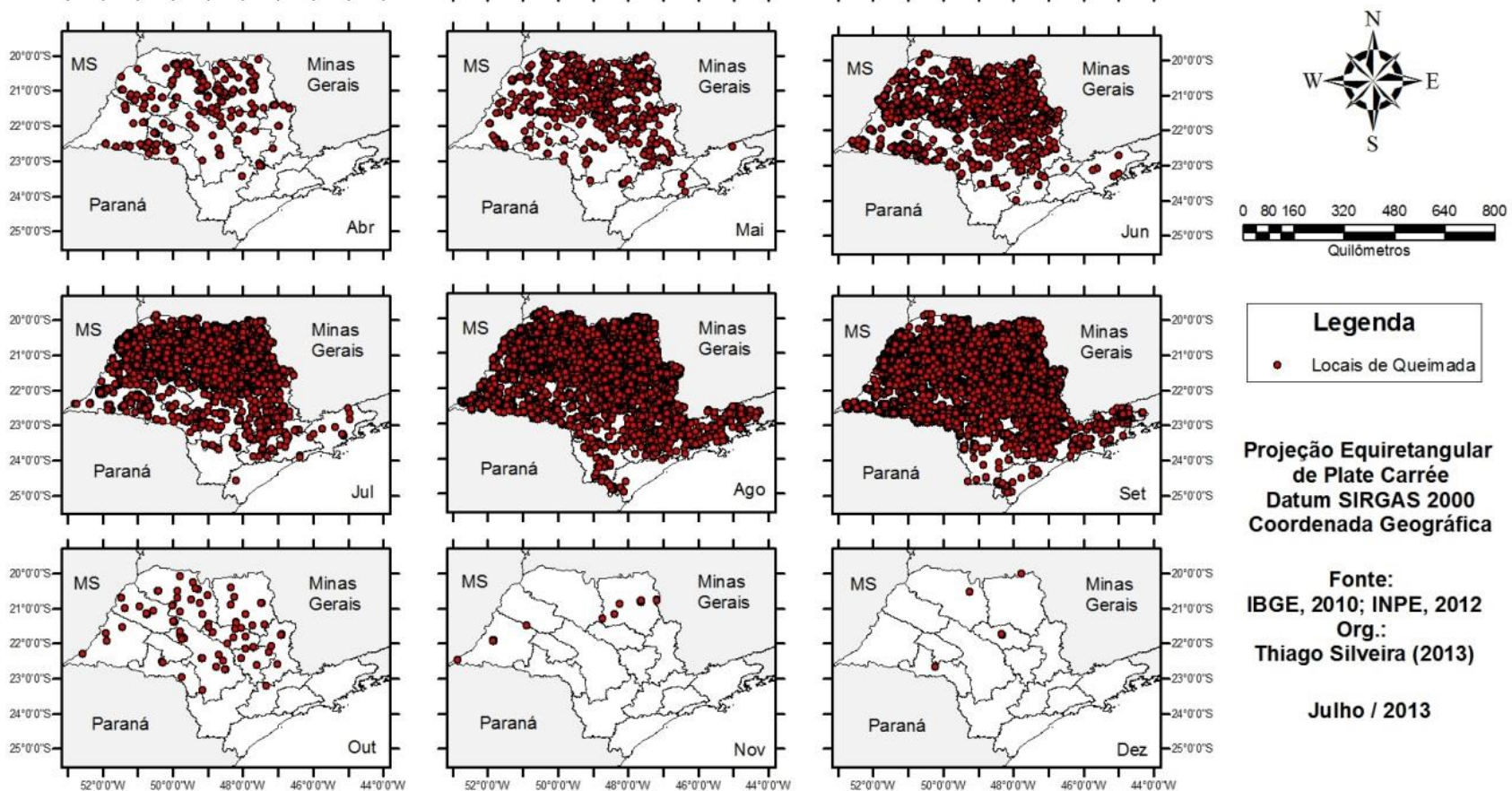

Julho / 2013

Mapa 3: Mapa de queimada de biomassa no estado de São Paulo em 2010.

Fonte: IBGE e INPE

A mancha que se forma nos meses de julho, agosto e setembro são patentes, justamente no período de colheita. Cada ponto do

Mapa 3 significa uma queima de biomassa, não diferenciando da queima em canaviais. Para isso foi feito o

Mapa 4, mostrando toda a extensão da área canavieira em São Paulo e todos os eventos de queima em 2010, depois disso mapeou-se os locais de queima em canaviais, resultando no quadro à direita do mapa. Vê-se que nesse caso, Ribeirão Preto e São José do Rio Preto são exemplos de locais onde a queima em canaviais são significativas. 
Com as condições atmosféricas propícias, como mostrado na Prancha de Croquis 1 como a falta de ventos por quase 24 horas entre os dias 16 e 17 de junho, acabou-se atingindo o pico de poluição atmosférica por $\mathrm{CO}$ e o segundo maior de particulados por conta da convergência de ventos, mostradas em $850 \mathrm{mb}$, próxima a superfície terrestre.

\section{Mapa de Queimadas em Áreas de Colheita de Cana de Açúcar em 2010}

Área de Colheita de Cana em 2010

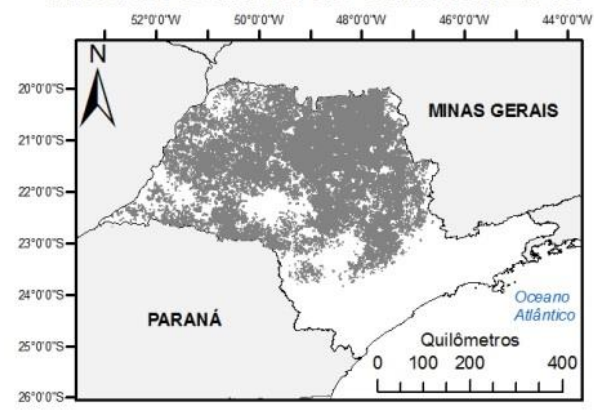

Densidade da Queima de Biomassa em 2010

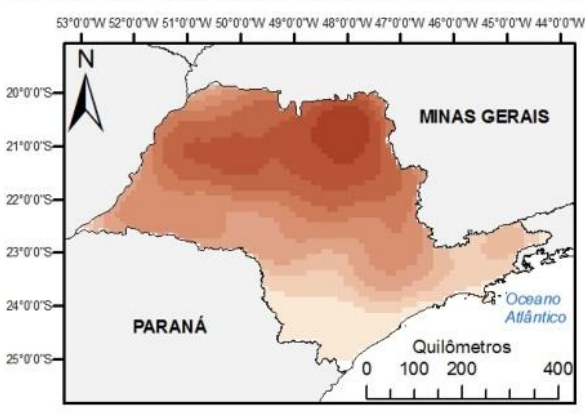

Projeção Equiretangular de Plate Carrée

Fonte: Datum SIRGAS 2000 IBGE, 2010; INPE, 2012 Coordenada Geográfica Org.:

Área Onde Houve Queima no Canavial

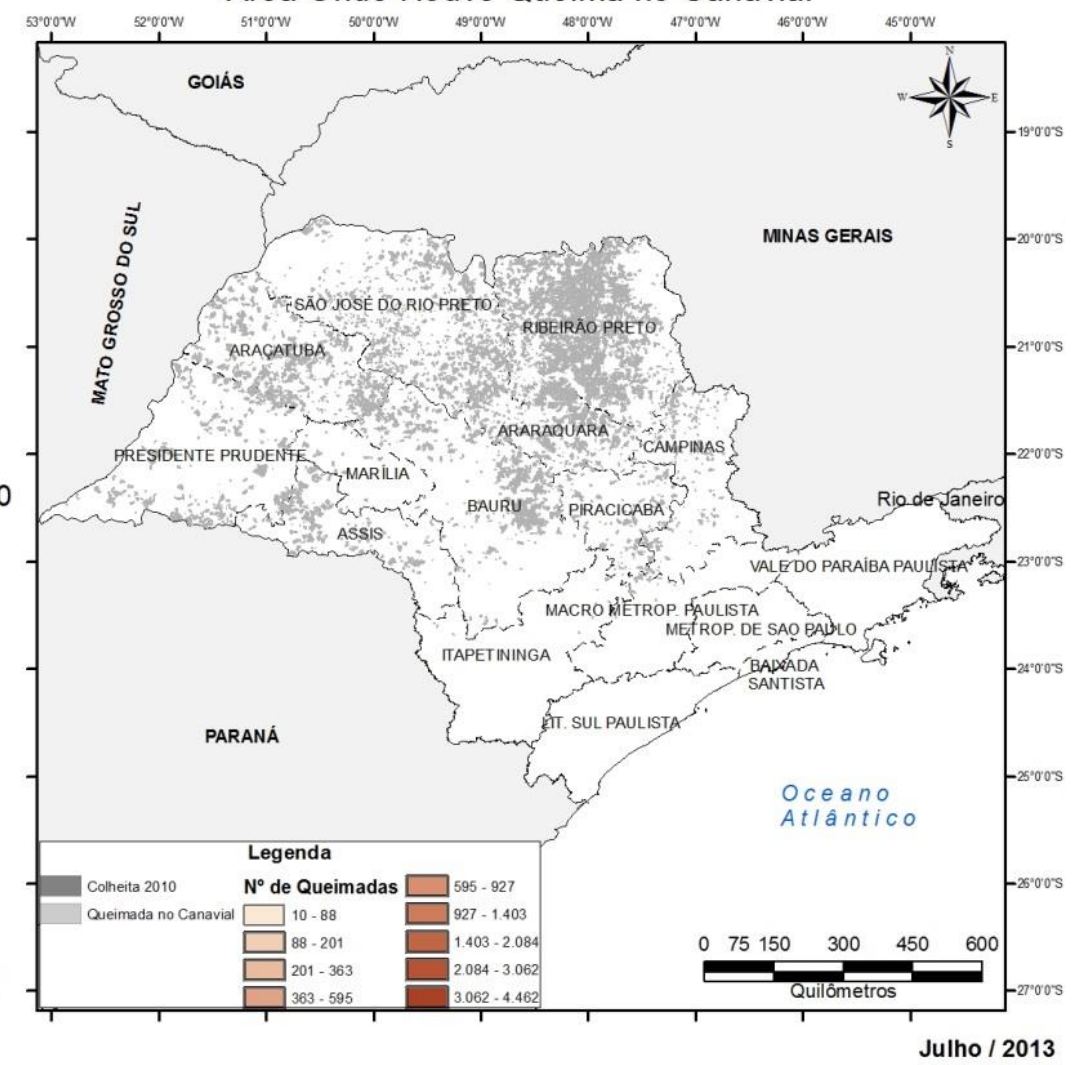

Mapa 4: Mapa de queimadas em áreas de colheita de cana

Fonte: IBGE e INPE 
vento em $850 \mathrm{mb}(\mathrm{m} / \mathrm{s})$ as 06Z16JUN 2010
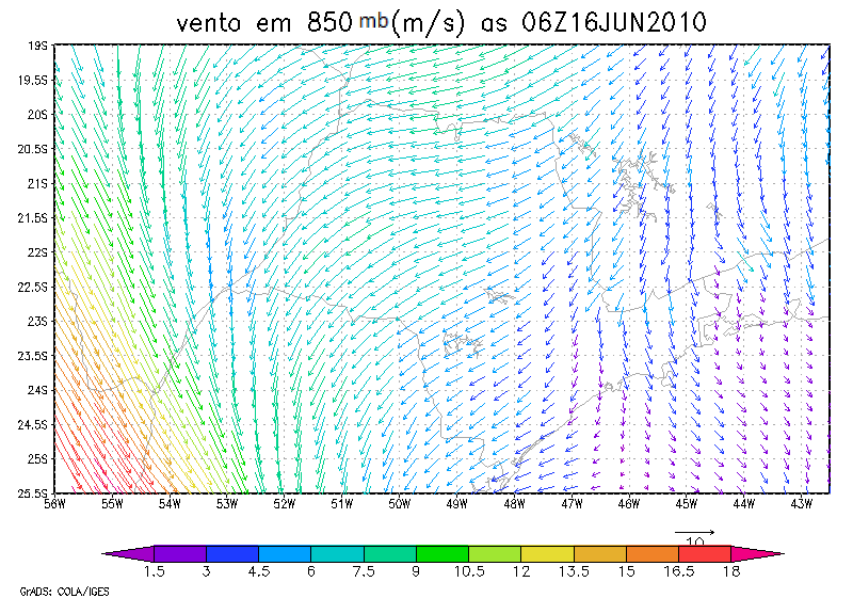

vento em $850 \mathrm{mb}(\mathrm{m} / \mathrm{s})$ as 18Z16.JUN2010

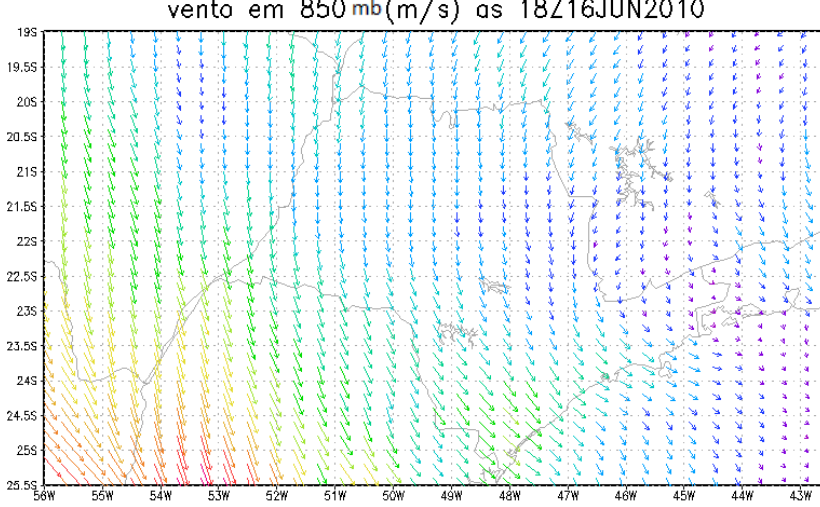

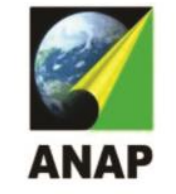


vento em $850 \mathrm{mb}(\mathrm{m} / \mathrm{s})$ as 00Z17Jun2010
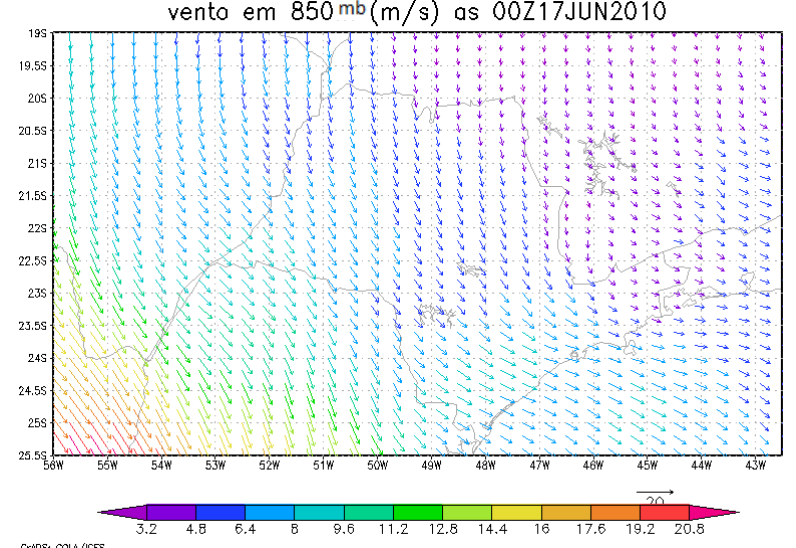

vento em $850 \mathrm{mb}(\mathrm{m} / \mathrm{s})$ as $12 Z 17 \mathrm{JU}$ N2010
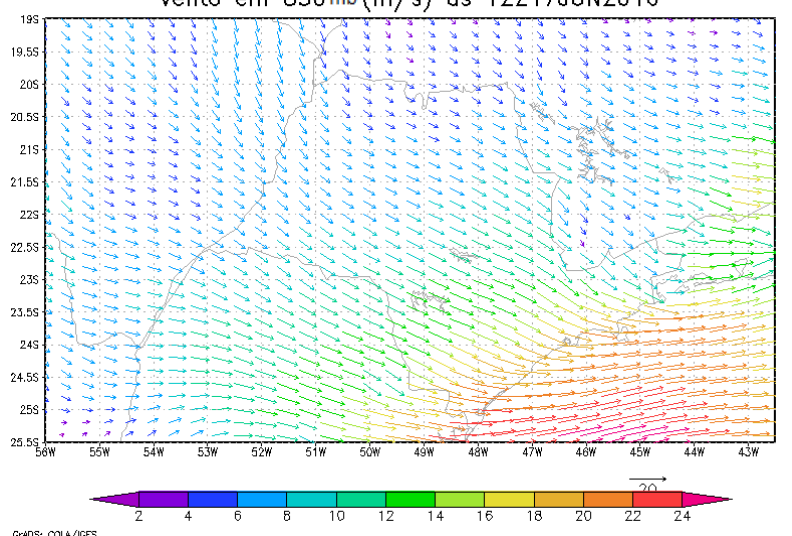

vento em $850 \mathrm{mb}(\mathrm{m} / \mathrm{s})$ as O0Z18Jun2010
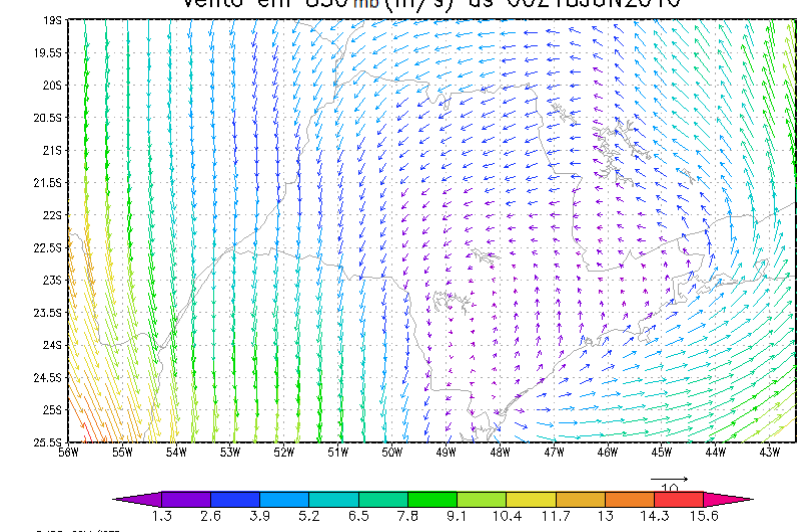

Prancha de Croquis 1. Evolução temporal dos ventos em SP de 16 a 18/06/2010 em 850 mb durante o máximo de CO. Fonte dos dados: Modelo ETA - INPE 


\section{CONSIDERAÇÕES FINAIS}

Não é possível atribuir inteiramente a má qualidade do ar nos meses de julho a setembro à queima da cana, apesar da grande coincidência entre os fenômenos. Mas a influência entre qualidade do ar/queima de biomassa é evidente, principalmente entre os municípios produtores e seus arredores. A rede de aferição de $\mathrm{CO}$ se restringe massivamente as Regiões Metropolitanas de São Paulo e Campinas, tornando as medições do interior deficitárias. Quanto ao material particulado a ampla rede de coleta e a sazonalidade apresentada mostraram o quanto essas emissões podem prejudicar o ar ao longo do ano, e observando o intenso número de queima em áreas de cana, pode-se concluir que a extinção dessa prática poderia contribuir diretamente diminuindo as taxas de $\mathrm{MP}_{10}$.

\section{REFERÊNCIAS}

ARBEX, A. M. et al. Queima de biomassa e efeitos sobre a saúde. Jornal Brasileiro de Pneumologia, São Paulo, 30, Mar-Abr 2004. Disponível em: http://www.scielo.br/scielo.php?script=sci_arttext\&pid=S180637132004000200015\&lang=pt.

BARROCAS, R. A queimada da cana-de-açúcar no estado de São Paulo: o exemplo de Iracemápolis. São Paulo: Universidade de São Paulo, 2001.

CAVALCANTE, M. S. A verdadeira história da cachaça. São Paulo: Sá, 2011.

FOOD AND AGRICULTURE ORGANIZATION OF THE UNITED NATIONS. Countries by commodity. FAOSTAT, Nova lorque, 2011. Disponivel em:

<http://faostat.fao.org/site/339/default.aspx>. Acesso em: 06 jun. 2013.

GONTIJO, G. A. B. et al. Detecção de queimadas e validação de focos de calor utilizando produtos de sensoriamento remoto. Anais XV Simpósio Brasileiro de Sensoriamento Remoto, abr-mai 2011. 7966-7973. Disponível em: http://www.Itid.inpe.br/sbsr2011/files/p1587.pdf. 
IBGE. Censo agropecuário. IBGE. Rio de Janeiro. 2006.

INSTITUTO NACIONAL DE METEOROLOGIA. Normais climatológicas 1961-1990. INSTITUTO NACIONAL DE METEOROLOGIA. Brasília. 1991. Disponível em: www.lce.esalq.usp.br/angelocci/NORMAIS.xls.

INSTITUTO NACIONAL DE PESQUISAS ESPACIAIS / CENTRO DE PREVISÃO DE TEMPO E ESTUDOS CLIMÁTICOS. Monitoramento do transporte de poluição antropogênica e de queimada na América do Sul, 1999. Disponivel em: $<$ http://meioambiente.cptec.inpe.br/modelo_cattbrams.php?lang=pt>. Acesso em: 12 fev. 2010. 